\title{
UTILIZAÇÃO DE URÉIA EM MISTURAS COM SULFATO DE AMÔNIO OU COM GESSO NA CULTURA DE MILHO(1)
}

\author{
Waldo Alejandro Ruben Lara Cabezas ${ }^{(2)}$, Carlos Ribeiro Rodrigues ${ }^{(3)}$, \\ Suelen Martins de Oliveira ${ }^{(4)}$ \& Elias Nascentes Borges ${ }^{(5)}$
}

\begin{abstract}
RESUMO
Aspectos qualitativos e quantitativos devem ser considerados na adubação nitrogenada de cobertura na cultura de milho. Este estudo teve por objetivo avaliar, nos municípios de Votuporanga (SP) e Uberlândia (MG), o efeito de diferentes misturas de grânulos, contendo N e S, na produtividade de milho. Em um Argissolo Vermelho eutrófico A moderado textura arenosa $\left(120 \mathrm{~g} \mathrm{~kg}^{-1} \mathrm{de}\right.$ argila) de Votuporanga, foram estimadas as perdas por volatilização de $\mathrm{N}_{-1} \mathrm{NH}_{3}$, das misturas de grânulos constituídas por uréia (U) e sulfato de amônio (SA), ou U e gesso agrícola, aplicadas no primeiro parcelamento de cobertura nitrogenada. Em Uberlândia, em Latossolo Vermelho ácrico típico fase Cerrado subcaducifólio muito argiloso (720 $\left.\mathrm{g} \mathrm{kg}^{-1}\right)$, foram determinados a distribuição de $\mathrm{N}$-inorgânico e S-sulfato em profundidade, após a aplicação das misturas em cobertura, e os custos de aplicação dessas fontes. Os experimentos foram instalados em delineamento de blocos casualizados, com quatro repetições, e as misturas de grânulos aplicadas em superfície, na entre linha de cultivo. Em Votuporanga, foram acompanhados dois experimentos: safra 2005/2006 e safrinha 2006. Na safra de 2005/2006, foram comparados quatro tratamentos de cobertura: testemunha, sem $\mathrm{N}$, uréia+sulfato de amônio farelado $\left(\mathrm{U}+\mathrm{SA}_{\mathrm{fa}}\right)$, uréia+gesso granulado $\left(\mathrm{U}+\mathrm{Gesso}_{\mathrm{gr}}\right)$ e uréia+gesso em pó (U+Gesso ${ }_{\text {pó }}$ ), aplicados em dois parcelamentos de $45 \mathrm{~kg} \mathrm{ha}^{-1}$ de $\mathrm{N}$ cada, nos estádios de cinco a seis folhas e 12 a 13 folhas. As perdas de $\mathrm{N}-\mathrm{NH}_{3}$ volatilizado em função do $\mathrm{N}$ aplicado foram de $45,9,56,6$ e $61,1 \%$ das misturas $\mathrm{U}+\mathrm{SA}_{\text {fa }}, \mathrm{U}+\mathrm{Gesso}_{\text {pó }} \mathrm{e}$ $\mathrm{U}+$ Gesso $_{\mathrm{gr}}$, respectivamente. A produtividade de grãos não mostrou diferença significativa entre os tratamentos, sendo, em média, de $5.362 \mathrm{~kg} \mathrm{ha}^{-1}$. Na safrinha, uréia+sulfato de amônio granulado $\left(\mathrm{U}+\mathrm{SA}_{\mathrm{gr}}\right)$ foi incluído nos tratamentos. Neste experimento, as misturas de grânulos foram aplicadas em doses de $50 \mathrm{~kg} \mathrm{ha}^{-1}$ de N cada, em cobertura, nos estádios de três a quatro folhas e seis a sete folhas. A
\end{abstract}

\footnotetext{
(1) Financiado pelo Convênio Embrapa-Petrobrás. Recebido para publicação em julho de 2007 e aprovado em julho de 2008.

(2) Pesquisador Científico nível IV, SAA-APTA-DDD Pólo Regional Noroeste Paulista. Caixa Postal 61, CEP 15500-970 Votuporanga (SP). E-mail: waldolar@terra.com.br ou waldolar@apta.sp.gov.br

(3) Engenheiro-Agrônomo, Dr. Solos e Nutrição de Plantas. Instituto de Ciências Agrárias, Universidade Federal de Uberlândia - UFU. Av. Amazonas s/n, Bloco 4C, Sala 127, Bairro Umuarama, CEP 38400-902 Uberlândia (MG). Bolsista Prodoc (CAPES). E-mail: carlos_rrodrigues@yahoo.com.br

(4) Graduanda de Agronomia. Instituto de Ciências Agrárias, UFU. Bolsista de Iniciação Científica. E-mail: suelenagro@yahoo.com.br

(5) Professor Associado. Instituto de Ciências Agrárias, UFU. E-mail: elias@ufu.br
} 
produtividade de grãos foi similar entre as fontes de U+SA e U+Gesso, sendo em média de $5.332 \mathrm{~kg} \mathrm{ha}^{-1}$. Em Uberlândia, foram comparados os cinco tratamentos testados no experimento - safrinha de Votuporanga. As misturas de grânulos foram aplicadas em dose única de $90 \mathrm{~kg} \mathrm{ha}^{-1} \mathrm{de} \mathrm{N}$, no estádio de quatro a cinco folhas. Os maiores teores de $\mathrm{N}$-mineral total foram detectados na camada de 0 a $10 \mathrm{~cm}$ de profundidade, em todos os tratamentos (abaixo de $3 \mathrm{mg} \mathrm{dm}^{-3}$ ), diminuindo em profundidade, enquanto o $S$-sulfato concentrou-se entre as camadas de 10 a $60 \mathrm{~cm}$. Os tratamentos de U+Gesso e U+SA apresentaram, em média, produtividades de 11.364 e $10.300 \mathrm{~kg} \mathrm{ha}^{-1}$ de grãos, respectivamente. $O$ custo de aplicação de U+Gesso ${ }_{\text {gr }}$ foi $27,7 \%$ superior aos custos médios de aplicação de $U+\mathrm{SA}_{\mathrm{gr}}$ e U+SA $\mathrm{Sa}_{\mathrm{fa}}$, devido a seu menor teor de $\mathrm{N}$, e 7,8 \% superior em relação aos custos diretos totais por hectare. A mistura NK com aplicação posterior de U+Gesso ó́ apresentou custo de aplicação similar ao da U+Gesso ${ }_{\mathrm{gr}}$, devido à dupla operação de aplicação do primeiro. Os resultados em ambas as regiões permitem concluir que o milho respondeu de forma similar à aplicação em cobertura das fontes mistas, U+SA e U+Gesso, independentemente da granulometria dos produtos, e que os custos de aplicação das formas U+Gesso foram superiores aos das misturas U+SA.

Termos de indexação: mistura de grânulos, cobertura nitrogenada, volatilização de $\mathrm{N}-\mathrm{NH}_{3}$.

\section{SUMMARY: USE OF UREA IN MIX WITH AMMONIUM SULFATE OR GYPSUM IN THE CULTURE OF CORN}

Qualitative and quantitative aspects must be considered in the side-dressing fertilization in the cultivation of corn. This study aimed to evaluate in the counties of Votuporanga (SP) and Uberlândia (MG), the effect on productivity of corn using different mixtures of granules in the side-dressing fertilization, containing nitrogen $(N)$ and sulphur (S). In Votuporanga (SP), in an Argisol (120 $\mathrm{g} \mathrm{kg}^{-1}$ of clay) were estimated losses through volatilization of $\mathrm{NH}_{3}-\mathrm{N}$ granules mix consisting of urea $(U)+$ ammonium sulfate $(A S)$ or $U$ + Gypsum applied in the first split of nitrogen application. In Uberlândia (MG) in ácric Red Latossol typical Cerrado phase clayed (720 $\left.\mathrm{g} \mathrm{kg}^{-1}\right)$, was given the distribution of $\mathrm{N}$ - and $S$ inorganic sulphate in depth, after application the granules mix, and assessment of the costs of implementing these sources. The experiments were installed in randomized block design with four repetitions, and granules mix applied to surface in between the row of plants. In Votuporanga (SP), were installed two experiments: first crop 2005/2006 and second-crop 2006. In the first crop, four treatments of side-dressing were compared: zero NSK, urea+ammonium sulphate with different particles size $\left(U+A S_{f a}\right)$, urea+gypsum granulated $\left(U+\right.$ Gypsum $\left._{\text {gr }}\right)$ and urea+gypsum powder $\left(U+\right.$ Gypsum $\left._{\text {powder }}\right)$, applied in two times of $45 \mathrm{~kg} \mathrm{ha}{ }^{-1}$ of $N$ each, in the respective stages of five to six leaves and 12 to 13 leaves. The losses of $\mathrm{NH}_{3}-\mathrm{N}$ were 45.9, 56.6 and $61.1 \%$ of the $\mathrm{N}$-applied in the forms $U+A S_{f a}$, $U+$ Gypsum $_{\text {powder }}$ and $U+G y p s u m_{g r}$, respectively. In spite of the losses of $U+A S_{f a}$ to be inferior to the other two sources, the productivity didn't show significant difference among those treatments, being on average of $5.362 \mathrm{~kg} \mathrm{ha}^{-1}$. In the second crop, the treatment urea+ammonium sulphate granule $\left(U+A S_{g r}\right)$ was included. The formulations were applied in $N$ doses of $50 \mathrm{~kg} \mathrm{ha}{ }^{-1}$ each, in the stages of four and six to seven leaves, respectively. The grain productivity was similar between the sources of $U+A S$ and $U+G y p s u m$, being on average of $5.332 \mathrm{~kg} \mathrm{ha}^{-1}$. In Uberlândia $(M G)$, the same treatments as in second crop of Votuporanga (SP) were compared. The formulations were applied $N$ in a single dose of $90 \mathrm{~kg} \mathrm{ha}-1$ of $N$ in the corn stage of four to five leaves. The distribution of total mineral- $N$ and sulphate-S were evaluated in depth until $60 \mathrm{~cm}, 30$ days after the application of the formulations in side-dressing. The largest concentrations of total mineral- $N$ were detected in the layer of $0-10 \mathrm{~cm}$ for all of the treatments (below $3 \mathrm{mg} \mathrm{dm}^{-3}$ ), decreasing in depth; however the sulfate-S was more concentrated among the layers of 10 down to $60 \mathrm{~cm}$. The treatments of $U+G y p s u m$ presented the largest productivities, on average of $11.364 \mathrm{~kg} \mathrm{ha}^{-1}$, in relation to the sources of $U+A S\left(10.300 \mathrm{~kg} \mathrm{ha}^{-1}\right)$. The cost of application of $U+G y p s u m_{g r}$ was $27,7 \%$ superior for the mean costs of application of $U+A S_{g r}$ and $U+A S_{f a}$, due to the smallest concentration of nitrogen and 7,8\% superior in relation to the total direct costs for hectare. The cost of application in relation to total cost of $\mathrm{NK}$ formulated with subsequent 


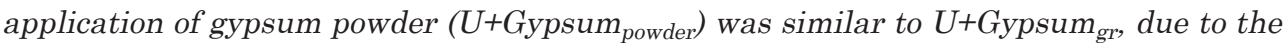
higher production cost and the duplication of application handling. The results of both areas allow to conclude that the corn response was similar for the side-dressing of the mixed sources of $U+A S$ and $U+G y p s u m$, independently of the particle size and in soils of different texture, and that the costs of application of the forms urea+Gypsum, were superior to the formulated mixtures $U+A S$.
\end{abstract}

Terms of indexation: granulated mixtures, side-dressing, $\mathrm{NH}_{3}-\mathrm{N}$ volatilization.

\section{INTRODUÇÃO}

Embora o S seja requerido em quantidade similar à do $\mathrm{P}$ pelas culturas, não tem recebido a devida atenção ao longo dos anos. Atualmente, em virtude da utilização de fertilizantes concentrados, que não o trazem em sua formulação, sua deficiência tornou-se ainda maior. Baixo teor de S no esterco, declínio no uso de defensivos contendo $\mathrm{S}$ e, devido à regulação das emissões atmosféricas gasosas de $\mathrm{S}$, têm influenciado os rendimentos e a qualidade dos cultivos. Essencial na síntese de proteínas, o $\mathrm{S}$ é constituinte dos aminoácidos metionina, cisteína, cistina e taurina (Scherer, 2001; Vitti \& Heinrichs, 2006). Assim, a adubação em cobertura deve contemplar a utilização de fertilizantes nitrogenados e sulfurados aplicados conjuntamente. Normalmente ocorre desbalanceamento quando a ênfase é dada unicamente ao N. De acordo com Bull \& Cantarella (1993), citando alguns autores, as máximas produções de massa de matéria seca (MMS) e de proteína no milho ocorrem numa estreita relação entre os conteúdos de $\mathrm{N}$ e de S protéicos. Vitti \& Heinrichs (2006) citaram as misturas U+SA (1:1 em produto), sulfonitrato de amônio (75 \% de nitrato de amônio e $25 \%$ de SA), nitrosulfato de amônio (1:1 em produto) de U+S elementar (10 a $30 \%$ de S) como fontes de aplicação conjuntas de N e S. Entretanto, o gesso agrícola aplicado com $\mathrm{U}$, em que o gesso é disponível em grande quantidade como resíduo da indústria de fertilizantes (Sobrinho et al., 2007), seria uma alternativa menos onerosa e de maior acessibilidade para o produtor.

Este estudo objetivou comparar o efeito de fontes nitrogenadas de cobertura, contendo uréia+sulfato de amônio e uréia+gesso, na produtividade de milho em dois solos de texturas diferentes, na região do Noroeste Paulista (Votuporanga) e do Triângulo Mineiro (Uberlândia). A volatilização de $\mathrm{N}-\mathrm{NH}_{3}$ das fontes foi quantificada em Votuporanga e, no município de Uberlândia, foi avaliada a distribuição de N-mineral e S-sulfato em profundidade e avaliados os custos de aplicação dessas fontes.

\section{MATERIAL E MÉTODOS}

Este estudo apresenta resultados do segundo ano aos obtidos na safra 2004/2005 em Uberlândia. Na safra 2005/2006, foi realizado mais um experimento nesse município e mais dois no município de Votuporanga.

\section{Votuporanga}

\section{Experimento 1: safra 2005/2006}

O experimento foi realizado no Pólo Regional Noroeste Paulista da APTA-SAA (Agência Paulista de Tecnologia dos Agronegócios da Secretaria do Estado de São Paulo), localizado em Votuporanga, estrada municipal Votuporanga-Nhandeara, $\mathrm{km} 04$.

Quanto ao histórico da área, na safra 2003/2004 foi cultivada com soja, variedade IAC-18, obtendo-se produtividade média de $2.500 \mathrm{~kg} \mathrm{ha}^{-1}$ de grãos. $\mathrm{Na}$ safra 2004/2005, foi cultivada com milho, híbrido ALPiratininga, obtendo-se $2.700 \mathrm{~kg} \mathrm{ha}^{-1}$ de grãos, devido a um acentuado veranico. Nas entressafras, a área permaneceu em pousio, sujeita ao crescimento vegetativo espontâneo, sem revolvimento do solo. A análise química do Argissolo (120 g kg-1 de argila) foi efetuada em maio de 2005 na camada de 0 a $20 \mathrm{~cm}$ de profundidade, apresentando $\mathrm{pH}\left(\mathrm{CaCl}_{2}\right)$ de 5,8; $\mathrm{P}$ (resina) de $33 \mathrm{mg} \mathrm{dm}^{-3}, \mathrm{~K}$ (resina) de $1,4 \mathrm{mmol}_{\mathrm{c}} \mathrm{dm}^{-3}$, V de $71 \%$, CTC 51,4 mmol $_{\mathrm{c}} \mathrm{dm}^{-3}$ e MO de $12 \mathrm{~g} \mathrm{dm}^{-3}$. As análises foram realizadas no laboratório de fertilidade de solo do IAC-Campinas (SP).

$\mathrm{O}$ dessecamento da área experimental foi realizado em 26/10/2005 com 2,0 L ha-1 de glifosate + 1,0 L ha-1 de 2,4-D. A rebrota do Acanthospermum australe (carrapicho) foi controlada pela adição de 1,0 L ha-1 de glifosate em 12/11/2005.

O milho híbrido simples precoce 30F35 (Pioneer) foi semeado em 23/11/2005, quando as chuvas começaram a regularizar-se. Foi semeado em espaçamento de 0,8 m entrelinhas, para uma população projetada de 60.000 plantas ha $^{-1}$, com adubação de base de $370 \mathrm{~kg} \mathrm{ha}^{-1}$ de 8-28-16, obtida a partir de sulfato de amônio, MAP, superfosfato simples, superfosfato triplo e KCl. Esta mistura é a mais utilizada na região para a cultura de milho. Foi utilizada a semeadura PST2-Super Tatu Marchesan, de quatro linhas, com haste escarificadora. A semente foi tratada com inseticida, e o controle de invasoras foi feito com aplicação de herbicida pós-emergente em 25/11/2005 e, posteriormente, em 11/01/2006.

$\mathrm{Na}$ adubação de cobertura foram testados quatro tratamentos de misturas de grânulos NSK, em delineamento de blocos casualizados, com quatro repetições: testemunha, sem aplicação de $\mathrm{N}$; 
uréia+sulfato de amônio farelado $\left(\mathrm{U}+\mathrm{SA} \mathrm{fa}_{\mathrm{fa}}\right)$, como 24:06:20, relação $\mathrm{N}: \mathrm{S}=4,0$; uréia+gesso granulado $\left(\mathrm{U}+\mathrm{Gesso}_{\mathrm{gr}}\right.$ ), como 15:05:19, relação $\mathrm{N}: \mathrm{S}=3,0$; e uréia+gesso em pó (U+Gesso pó), como mistura 23:00:30, com aplicação de Gesso pó separadamente sobre a faixa da aplicação prévia da mistura NK. As misturas de grânulos foram cedidas pela empresa Serrana Fertilizantes, integrante do Grupo Bunge Fertilizantes. A mistura U+SA $\mathrm{gr}_{\mathrm{gr}}$ não foi incluída neste experimento. As misturas de grânulos foram aplicadas em dois parcelamentos de $45 \mathrm{~kg} \mathrm{ha}^{-1}$ cada, em superfície, na entre linha de plantas aos 22 dias (19/ 12/2005) e 71 dias após emergência, nos estádios respectivos de cinco a seis folhas e 12-13 folhas. Cada parcela constituiu-se de $50 \mathrm{~m}$ de comprimento e oito linhas de plantas com espaçamento de $0,8 \mathrm{~m}$.

Foram estimadas as perdas de $\mathrm{N}-\mathrm{NH}_{3}$ das misturas aplicadas no primeiro parcelamento, utilizando-se o coletor semi-aberto estático adaptado e calibrado por Lara Cabezas et al. (1999). Aleatoriamente, foram instaladas oito unidades coletoras de amônia em cada tratamento, no dia 19/12/2005, sobre o fertilizante aplicado em superfície, na entre linha, sendo efetuadas cinco amostragens em intervalos de quatro a cinco dias. Os discos absorvedores de $\mathrm{N}-\mathrm{NH}_{3}$ foram embebidos em solução de $1 \mathrm{~mol} \mathrm{~L}^{-1}$ de $\mathrm{H}_{3} \mathrm{PO}_{4} \mathrm{e}$ glicerina como agente umidificante (Cantarella, $\mathrm{H}$., comunicação pessoal). As amostras coletadas foram mantidas em temperatura de $5{ }^{\circ} \mathrm{C}$, até a determinação das análises. A extração do $\mathrm{N}-\mathrm{NH}_{3}$ volatilizado dos discos absorvedores foi efetuada por lavagens sucessivas com KCl $1 \mathrm{~mol} \mathrm{~L}^{-1}$ e posterior destilação Kjeldahl por arraste de vapor. Os valores foram expressos em percentual de perda em relação ao $\mathrm{N}$ aplicado. As análises foram realizadas no laboratório de Fertilidade de Solo do IAC-Campinas (SP).

Em 16/02/2006, logo após o florescimento do milho, para a determinação de MMS e do teor de $\mathrm{N}$ e S na parte aérea, foram colhidas plantas de $1 \mathrm{~m}$ (três repetições por parcela), cortadas a $0,05 \mathrm{~m}$ da superfície do solo, incluindo caule, folhas verdes, senescentes e espigas. As plantas foram pesadas, trituradas e homogeneizadas, para posterior subamostragem e secagem em estufa a $60^{\circ} \mathrm{C}$ até peso constante. As subamostras secas foram embaladas e encaminhadas ao Laboratório Unithal em Campinas (SP) para análises e posterior cálculo da quantidade acumulada de nutrientes na planta.

A colheita foi efetuada em 04/05/2006, determinando-se a população de plantas com espigas, o número de espigas por planta e a produtividade de grãos, corrigindo-se a umidade para $130 \mathrm{~g} \mathrm{~kg}^{-1}$. Em cada parcela, foram colhidas as espigas com palha de três linhas com $15 \mathrm{~m}$ de comprimento, debulhadas e realizadas as determinações.

Foi efetuada análise de variância, e as médias foram comparadas pelo teste t (Student) a $5 \%$, quando verificada significância pelo teste de F. Os dados obtidos das perdas de $\mathrm{N}$-volatilizado foram avaliados por análises de variância, em delineamento inteiramente casualizado, e as médias comparadas pelo teste de $t$ (Student) a $5 \%$.

\section{Experimento 2: safrinha 2006}

O experimento foi instalado em 06/02/2006, no mesmo solo e talhão utilizados na safra. Foi semeado o milho híbrido 30F35, com espaçamento de $0,8 \mathrm{~m}$ entre linhas, para uma população de plantas projetada de $55.000 \mathrm{ha}^{-1}$. Como adubação de semeadura, foram aplicados $250 \mathrm{~kg} \mathrm{ha}^{-1}$ de 08-28-16. Na adubação de cobertura, foram instalados cinco tratamentos de misturas de grânulos NSK, em delineamento de blocos inteiramente casualizados, com quatro repetições: testemunha, sem aplicação de $\mathrm{N}$; $\mathrm{U}+\mathrm{Sa}_{\mathrm{fa}}$, como 24:06:20, relação N:S = 4,0; $\mathrm{U}+\mathrm{Sa}_{\mathrm{gr}}$, como 24:06:20, relação N:S = 4,0; U+Gessogr, como 15:05:19, relação $\mathrm{N}: \mathrm{S}=3,0 ;$ e U+Gesso pó, como mistura 23:00:30, com aplicação do gesso em pó separadamente, sobre a faixa da aplicação prévia da mistura NK. As parcelas foram de $20 \mathrm{~m}$ de comprimento e 6,4 m de largura, incluindose oito linhas de plantas. O primeiro parcelamento foi realizado em 17/02/2006, no estádio de quatro folhas e o segundo em 10/03/2006, no estádio de seis a sete folhas, em doses equivalentes de $50 \mathrm{~kg} \mathrm{ha}^{-1}$ de $\mathrm{N}$ cada.

Neste experimento foi avaliado o número de plantas com espigas, o número de espigas por planta e a produtividade de grãos. Em 03/06/2006, foram colhidas as espigas correspondentes às duas linhas centrais, de oito metros de comprimento. A umidade de grãos foi corrigida para $130 \mathrm{~g} \mathrm{~kg}^{-1}$.

\section{Uberlândia}

\section{Experimento 3: safra 2005-2006}

O experimento foi conduzido na Fazenda Floresta do Lobo, Reflorestadora Pinusplan Ltda., Uberlândia (MG), km 93, rodovia BR 050, em área recém destocada de Pinus caribaea.

O milho híbrido simples 2B710 foi semeado em um Latossolo Vermelho ácrico típico fase cerrado (710 $\mathrm{g} \mathrm{kg}^{-1}$ de argila) relevo plano, em 04/11/2005. A amostragem de solo para a camada de 0 a $20 \mathrm{~cm}$ apresentou $\mathrm{pH}\left(\mathrm{CaCl}_{2}\right)$ de 4,9, 18,0 $\mathrm{mg} \mathrm{dm}^{-3}$ de $\mathrm{P}$, $2,2 \mathrm{mmol}_{\mathrm{c}} \mathrm{dm}^{-3} \mathrm{de} \mathrm{K}, 75,2 \mathrm{mmol}_{\mathrm{c}} \mathrm{dm}^{-3} \mathrm{de}$ CTC, $44,2 \%$ de $\mathrm{V}, 36 \mathrm{~g} \mathrm{dm}^{-3}$ de $\mathrm{MO}$ e $9,0 \mathrm{mg} \mathrm{dm}^{-3}$ de S. A análise química foi baseada no método descrito por Raij et al. (2001), sendo realizada no laboratório do Instituto de Ciências Agrárias da Universidade Federal de Uberlândia (MG). Em julho de 2005, o solo foi arado, gradeado, nivelado, sendo incorporadas $1,5 \mathrm{tha}^{-1} \mathrm{de}$ calcário dolomítico e $1,5 \mathrm{t} \mathrm{ha}^{-1}$ de gesso. A adubação de base foi feita com $350 \mathrm{~kg} \mathrm{ha}^{-1}$ de 19:32:06, sendo aplicados 47,3 $\mathrm{kg} \mathrm{ha}^{-1}$ de N-uréia, $210 \mathrm{~kg} \mathrm{ha}^{-1}$ de MAP e $84 \mathrm{~kg} \mathrm{ha}^{-1}$ de $\mathrm{K}_{2} \mathrm{O}-\mathrm{KCl}$. Foi utilizado espaçamento de 0,5 m entre linhas, com uma população projetada para 68.000 plantas ha $^{-1}$. O experimento foi estabelecido em delineamento de blocos inteiramente casualizados, com cinco tratamentos de adubação em cobertura e quatro repetições. Os tratamentos de 
misturas de grânulos NSK foram: testemunha (sem aplicação de $\mathrm{N}), 24: 06: 20$ na forma $\mathrm{U}+\mathrm{SA}_{\mathrm{fa}}$ com relação $\mathrm{N}: \mathrm{S}$ de 4,0; U+SA $\mathrm{Sr}_{\text {r }}$ como 15:05:19 na forma $\mathrm{U}+\mathrm{Gesso}_{\mathrm{gr}}$, com relação N:S de 3,0; e a mistura 23:00:30 com aplicação do gesso em pó separadamente, sobre a faixa da aplicação prévia da mistura NK. A adubação de cobertura foi realizada em 7/12/2005, no estádio de quatro a cinco folhas expandidas, em dose de $90 \mathrm{~kg} \mathrm{ha}^{-1}$ de N, na superfície da entre linha. Cada repetição foi constituída de 12 linhas de plantas, espaçadas de 0,5 e $50 \mathrm{~m}$ de comprimento total.

No estádio de pleno florescimento, ocorrido 30 dias após a aplicação dos adubos, foi efetuada amostragem da folha oposta e abaixo da espiga, para avaliação do teor de N. Na ocasião, foram colhidas 15 folhas de cada repetição em cada tratamento. O material foi preparado segundo indicação de Malavolta et al. (1997).

Nessa mesma época, foi efetuada a amostragem de solo, nas profundidades de 0 a 10, 10 a 20, 20 a 40 e 40 a $60 \mathrm{~cm}$, para determinação de N-mineral total (Cantarella \& Trivelin, 2001) e S-sulfato por turbidimetria, segundo método preconizado por Cantarella \& Prochnow (2001). Foram coletadas sete subamostras na entre linha de cada parcela, sobre a faixa adubada. As subamostras foram misturadas, para compor uma amostra de cada repetição. A terra foi passada em peneira de $2 \mathrm{~mm}$ e as amostras secas ao ar (TFSA). As análises foram realizadas nos laboratórios do Instituto de Ciências Agrárias da UFUUberlândia (MG).

Na colheita, em 17/04/2006, foram separadas as espigas sem palha de $20 \mathrm{~m}$ das duas linhas centrais, sendo determinada a umidade de grãos e corrigido o peso para $130 \mathrm{~g} \mathrm{~kg}^{-1}$. Amostras de grãos foram secas em estufa com circulação forçada de ar a $60^{\circ} \mathrm{C}$ até peso constante, para determinação dos teores de $\mathrm{NeS}$ nos grãos.

Foram determinados os custos diretos de aplicação das misturas de grânulos em cobertura e a proporção desses custos em relação aos custos diretos totais, para a produção de um hectare de milho, conforme relatado por Richetti (2007).

\section{RESULTADOS E DISCUSSÃO}

\section{Votuporanga (SP)}

\section{Experimento 1: safra 2005/2006}

A figura 1 mostra os dados climáticos de pluviosidade e temperaturas máximas e mínimas durante o período de produção de grãos na safra 2005/2006 e safrinha 2006 na cultura de milho, estabelecida em solo sem preparo, na Unidade Experimental de Votuporanga.

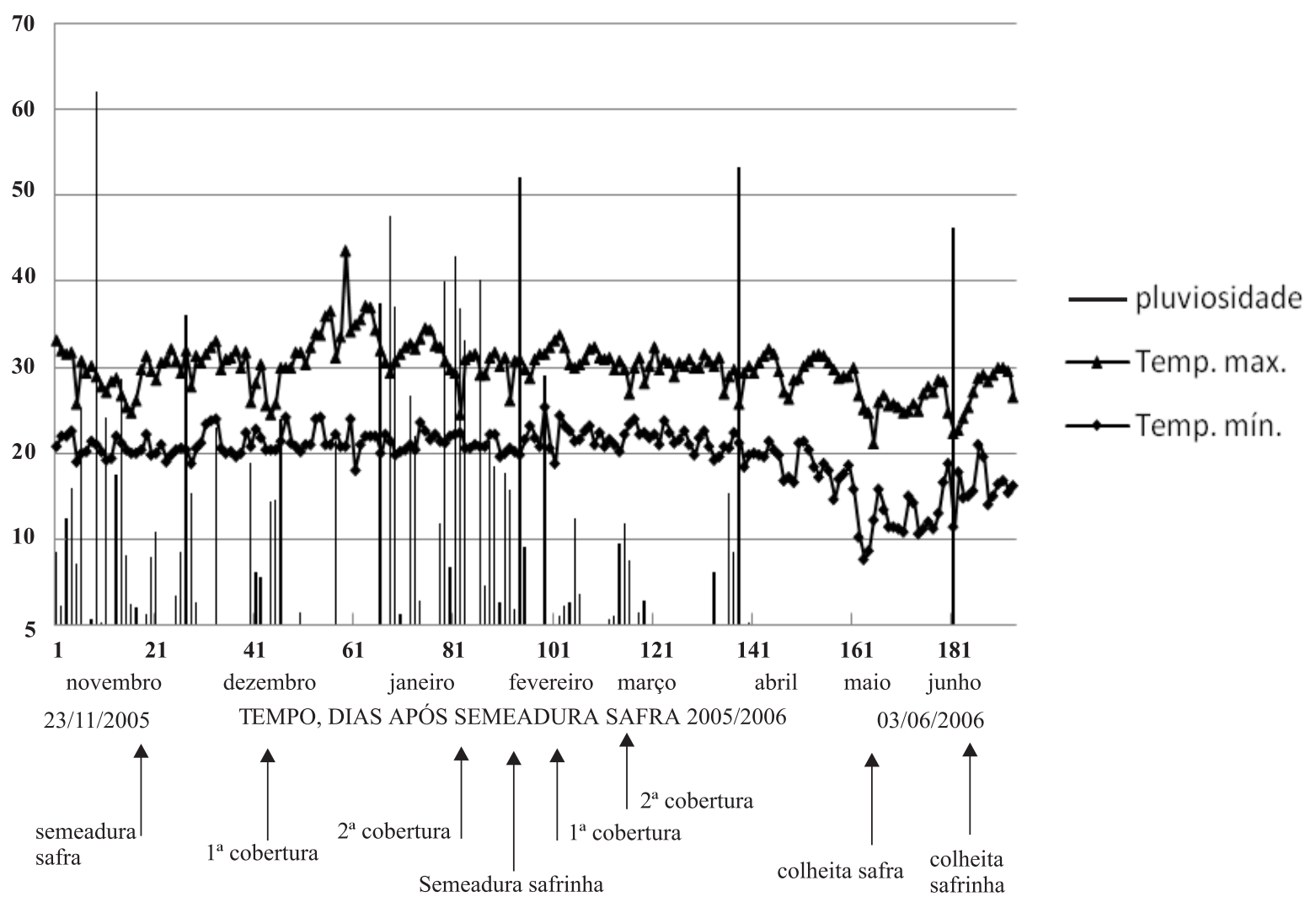

Figura 1. Distribuição da precipitação pluvial entre os meses de novembro de 2005 até início de junho de 2006, incluindo a safra 2005/2006 e safrinha 2006, no Pólo Regional Noroeste Paulista (SP). 
Logo após a semeadura de milho, foram registrados $134 \mathrm{~mm}$ de pluviosidade nos primeiros 10 dias, de forma intermitente, ocorrendo regularmente durante o mês de dezembro. Durante o mês de janeiro houve dois veranicos, de dez e oito dias cada, e altas temperaturas (acima de $35^{\circ} \mathrm{C}$ ), que devem ter influenciado a fase de enchimento de grãos. Novamente, durante o mês de fevereiro de 2006, a pluviosidade normalizou-se, sendo março, novamente, um mês de pluviosidade irregular. As coberturas nitrogenadas, na ocasião da aplicação das misturas, foram seguidas por pluviosidade abundante, o que, na condição de solo arenoso, deve ter influenciado a eficiência de recuperação de N pela planta (Figura 1). Isso, somado à aplicação tardia da segunda cobertura, deve ter influenciado a produtividade.

As perdas acumuladas de $\mathrm{N}-\mathrm{NH}_{3}$ provenientes das

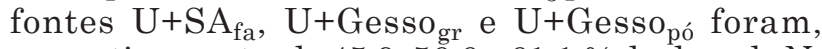
respectivamente, de 45,9, 56,6 e $61,1 \%$ da dose de $\mathrm{N}$, após 22 dias da aplicação das fontes (Figura 2). As perdas de $\mathrm{U}+\mathrm{SA}_{\text {fa }}$ foram menores do que das outras fontes, as quais não apresentaram diferenças significativas entre si. O SA mostrou-se mais eficiente no controle das perdas gasosas provenientes principalmente do N-U, apesar do conhecido efeito inibidor da volatilização do gesso em cama de frango (Sampaio et al., 1999). Num trabalho precedente, em solo muito argiloso (Lara Cabezas \& Souza, 2008), as perdas de $\mathrm{U}+\mathrm{SA}_{\mathrm{fa}}$ e $\mathrm{U}+\mathrm{SA}_{\mathrm{gr}}$ foram inferiores às registradas neste estudo (27,7 e 37,9 \% do N-aplicado), mostrando que a textura arenosa favorece as perdas gasosas, quando as fontes são aplicadas em superfície. De modo geral, os resultados obtidos por Silva et al. (1999) refletem diferenças em características e propriedades dos solos PV e LR, indicando perdas mais elevadas no primeiro (textura arenosa), em relação ao segundo (textura argilosa). Outros autores têm evidenciado resultados similares em relação à textura de solo (Buresh, 1987; Lara Cabezas, 1991), segundo os quais, em solo de textura arenosa e baixa CTC, a volatilização do N é mais expressiva. Cabe salientar que os $35 \mathrm{~mm}$ de chuva ocorridos após a aplicação dos fertilizantes em superfície provavelmente não foram suficientes para aprofundar as fontes. O processo posterior de evaporação de água levaria o $\mathrm{N}$ das fontes novamente à superfície, acentuado pelas altas temperaturas, favorecendo as perdas do N-U da solução de solo.

Como observado por Port et al. (2003), perdas significativas de $\mathrm{N}$ ocorreram logo após a aplicação das fontes, sendo inexpressivas quatro dias após.

Os resultados de produção de MMS e de $\mathrm{N}$ e $\mathrm{S}$ acumulados na parte aérea da planta, logo após o florescimento, dos tratamentos de cobertura nitrogenada, mostram que houve maior produção de MMS nos tratamentos que receberam as misturas em cobertura, em relação à testemunha (Quadro 1). Em termos de absorção de $\mathrm{N}$ pela planta, houve maior acúmulo desse nutriente nos tratamentos U+Gesso pó
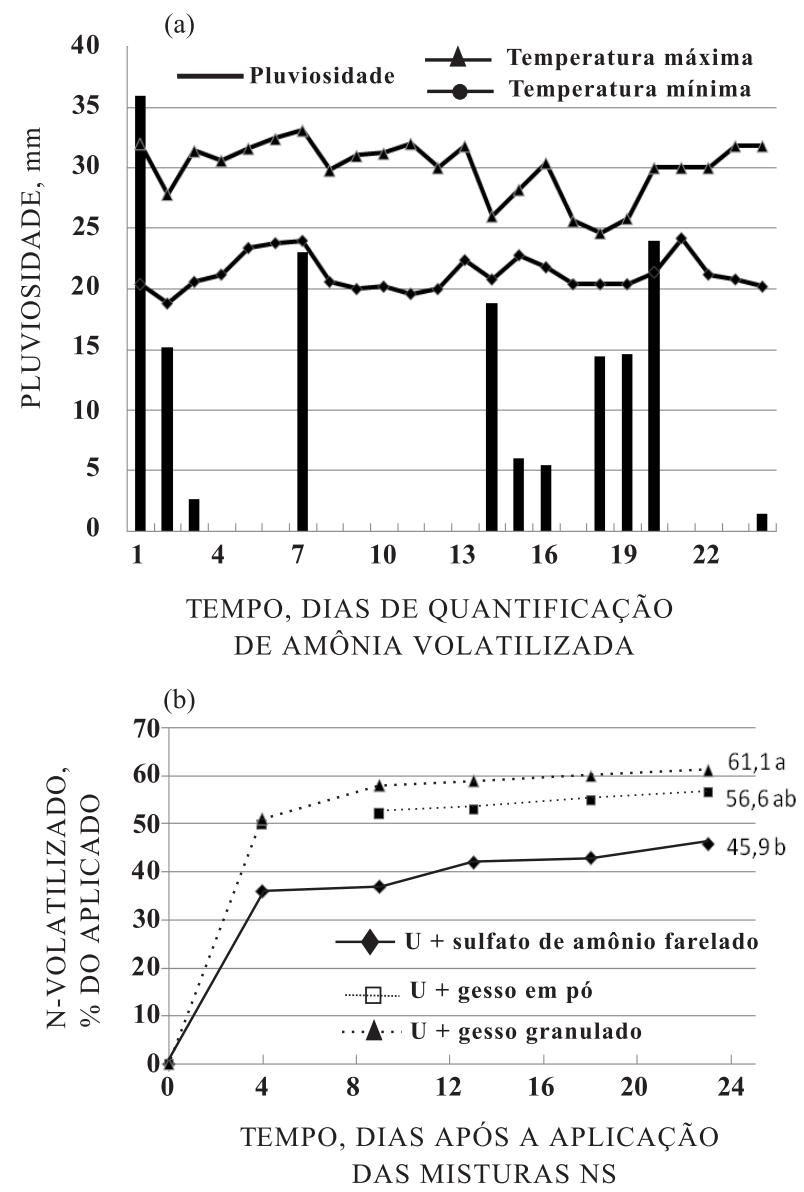

Figura 2. Distribuição da pluviosidade (a) no intervalo de tempo transcorrido na quantificação de $\mathrm{N}_{-} \mathrm{NH}_{3}$ volatilizado (b) proveniente das misturas uréia+sulfato de amônio e uréia+gesso aplicadas na primeira cobertura nitrogenada na cultura de milho, na safra 2005/2006, Votuporanga (SP). Entre as misturas, as médias seguidas de letras diferentes apresentam diferença significativa pelo teste de $\mathrm{t}$ (Student) a $5 \%$. DMS = 15,2; $\mathrm{CV}(\%)=19,1$.

$\left(145,7 \mathrm{~kg} \mathrm{ha}^{-1}\right)$ e U+SA $\mathrm{fa}_{\mathrm{f}}\left(136,0 \mathrm{~kg} \mathrm{ha}^{-1}\right)$ em relação a $\mathrm{U}+\mathrm{Gesso}_{\mathrm{gr}}$. Isso também foi verificado com o acúmulo de S. Apesar dessa esperada diferença em acúmulo, Epstein \& Bloom (2006) assinalam que N e S compartilham extraordinária versatilidade em reações de oxirredução, atributo fundamental no metabolismo de plantas. A testemunha, sem aplicação de N, como esperado, apresentou os menores valores de $\mathrm{N}$ e $\mathrm{S}$ acumulados na parte aérea.

A população de 50.297 plantas ha-1 foi inferior ao $^{-1}$ projetado de 60.000 plantas ha ${ }^{-1}$ para os tratamentos que receberam cobertura NSK (Quadro 2). A ausência de cobertura nitrogenada na testemunha influenciou ainda mais a população de plantas, apresentando valor médio de 43.722 plantas ha ${ }^{-1}$. Nessa condição, a concorrência das plantas por nutrientes, em solo de baixa fertilidade, teria influenciado a população de 
Quadro 1. Massa de matéria seca (MMS) da planta inteira de milho, sem raízes, coletada logo após o florescimento e quantidades acumuladas de nitrogênio e enxofre, sob fertilizantes de cobertura aplicados na safra 2005/2006, contendo uréia+sulfato de amônio e uréia+gesso.Votuporanga (SP) ${ }^{(1)}$

\begin{tabular}{|c|c|c|c|}
\hline Tratamento & MMS & $\mathbf{N}$ total acumulado & S total acumulado \\
\hline & & $\mathrm{kg} \mathrm{ha}^{-1}$ & - \\
\hline Testemunha & $10.245 \mathrm{~b}$ & $105,9 \mathrm{c}$ & $10,2 \mathrm{~b}$ \\
\hline $\mathrm{U}+\mathrm{SA}_{\mathrm{fa}}$ & $12.523 \mathrm{a}$ & $136,0 \mathrm{ab}$ & $11,9 a b$ \\
\hline $\mathrm{U}+\mathrm{Gessogr}_{\mathrm{gr}}$ & $11.713 \mathrm{ab}$ & $131,0 \mathrm{~b}$ & $12,1 \mathrm{ab}$ \\
\hline $\mathrm{U}+\mathrm{Gesso}_{\text {pó }}$ & $12.425 \mathrm{a}$ & $145,7 \mathrm{a}$ & 13,5 a \\
\hline DMS (entre tratamentos) & 1.967 & 11,6 & 2,0 \\
\hline CV (\%) & 10,5 & 5,6 & 10,6 \\
\hline
\end{tabular}

(1) Em cada coluna, as médias seguidas de letras iguais não diferem significativamente a 0,05 pelo teste de $\mathrm{t}$ (Student). U+SA $\mathrm{f}_{\mathrm{f}}=$

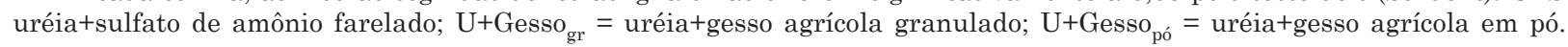

Quadro 2. População de plantas com espigas, número de espigas por planta e produtividade de grãos, sob fertilizantes de cobertura aplicados na safra 2005/2006 e safrinha 2006, contendo uréia+sulfato de amônio e uréia+gesso. Votuporanga (SP) ${ }^{(1)}$

\begin{tabular}{|c|c|c|c|}
\hline Tratamento & População de plantas & Espigas por planta & Produtividade \\
\hline & plantas $\mathrm{ha}^{-1}$ & & $\mathrm{~kg} \mathrm{ha}^{-1}$ \\
\hline & \multicolumn{3}{|c|}{ Safra $2005 / 2006$} \\
\hline Testemunha & $43.722 \mathrm{~b}$ & 0,91 & $3.994 \mathrm{~b}$ \\
\hline $\mathrm{U}+\mathrm{SA}_{\mathrm{fa}}$ & $49.653 \mathrm{ab}$ & 0,93 & $5.227 \mathrm{a}$ \\
\hline $\mathrm{U}+$ Gessogr $_{\mathrm{gr}}$ & $51.320 \mathrm{a}$ & 0,94 & $5.233 \mathrm{a}$ \\
\hline $\mathrm{U}+\mathrm{Gesso}_{\mathrm{pó}}$ & $52.917 \mathrm{a}$ & 0,95 & $5.627 \mathrm{a}$ \\
\hline DMS (entre tratamentos) & 6.539 & $0,05 \mathrm{~ns}$ & 1.100 \\
\hline \multirow[t]{2}{*}{ CV (\%) } & 8,3 & 3,5 & 13,7 \\
\hline & & Safrinha 2006 & \\
\hline Testemunha & 50.586 & - & $2.754 \mathrm{~b}$ \\
\hline $\mathrm{U}+\mathrm{SA}_{\mathrm{fa}}$ & 51.172 & - & $4.961 \mathrm{a}$ \\
\hline $\mathrm{U}+\mathrm{SA}_{\mathrm{gr}}$ & 55.210 & - & $5.977 \mathrm{a}$ \\
\hline $\mathrm{U}+\mathrm{Gessogr}_{\mathrm{gr}}$ & 52.930 & - & $5.450 \mathrm{a}$ \\
\hline $\mathrm{U}+$ Gesso ó & 51.953 & - & $4.938 \mathrm{a}$ \\
\hline DMS (entre tratamentos) & 4.942 n.s. & - & 1.051 \\
\hline CV $(\%)$ & 6,2 & & 14,2 \\
\hline
\end{tabular}

(1) Em cada coluna, dentro de cada época de cultivo, as médias seguidas de letras iguais, não diferem significativamente a 0,05 pelo teste de $\mathrm{t}$ (Student). U+SA $\mathrm{fa}_{\mathrm{f}}=$ uréia+sulfato de amônio farelado, U+Gesso $\mathrm{gr}_{\mathrm{gr}}=$ uréia+gesso agrícola granulado, U+Gesso $_{\text {pó }}=$ uréia+gesso agrícola em pó.

plantas com espigas e, conseqüentemente, a produtividade, como observado por Silva et al. (2003). Não foi observada diferença no número de espigas por planta (média de 0,93). Entre os tratamentos adubados com mistura U+SA e U+Gesso, não houve diferença significativa de produtividade, evidenciando que o gesso poderia substituir o SA como fonte de S, na adubação de cobertura.

\section{Experimento 2: safrinha 2006}

Pode-se observar que a semeadura efetuada no mês de fevereiro de 2006 favoreceu o crescimento e desenvolvimento da cultura pela freqüência da pluviosidade (Figura 1). Após a segunda quinzena de março, as chuvas ficaram irregulares, havendo registro no início do mês de abril, seguido de um longo período de estiagem, coincidindo com a queda da temperatura.

Não foi observada diferença na população de plantas entre os tratamentos, coerente com o estande programado, demonstrando que no experimento de safra houve problemas de calibração de maquinário e não de pragas de solo (Quadro 2). Não houve, também. diferenças de produtividade de grãos entre os tratamentos, independentemente da granulometria 
utilizada nas misturas. Em média, a produtividade foi de $5.332 \mathrm{~kg} \mathrm{ha}^{-1}$ nos tratamentos que receberam adubo de cobertura, em relação à testemunha: $2.754 \mathrm{~kg} \mathrm{ha}{ }^{-1}$. Novamente, esses resultados, como os obtidos na safra 2004/2005 em Uberlândia e na safra 2005/2006 em Votuporanga, mostram que a fonte SA, dependendo de sua disponibilidade e preço da matériaprima, poderia ser substituída pelo gesso na adubação de cobertura.

\section{Uberlândia (MG)}

\section{Experimento 3: safra 2005/2006}

$\mathrm{Na}$ época da aplicação da cobertura, houve regularidade na precipitação pluvial (Figura 3), o que deve ter contribuído para maior absorção de nutrientes pela planta.

Não houve diferença significativa entre os tratamentos adubados em cobertura e a testemunha (Figura 4a) quanto ao teor e distribuição em profundidade no solo, evidenciando que o $\mathrm{N}$ aplicado foi nitrificado, absorvido pela cultura ou, talvez, parte dele lixiviado para camadas mais profundas que as analisadas neste trabalho.

Em geral, o S-sulfato concentrou-se nas camadas de 10 a $40 \mathrm{~cm}$ de profundidade, com decréscimo na de 40 a 60 cm (Figura 4b). Scherer (2001) afirma que o sulfato é mais adsorvido na subsuperfície do solo em razão de cargas dependentes do $\mathrm{pH}$, visto que a $\mathrm{MO}$ e o acúmulo de fosfatos na superfície do solo são fatores bloqueadores de sítios de adsorção do sulfato. A testemunha apresentou os maiores valores de S-sulfato abaixo da camada de 0 a $10 \mathrm{~cm}$ de profundidade e acima de $50 \mathrm{mg} \mathrm{dm}^{-3}$ nas camadas de 10 a $40 \mathrm{~cm}$. Uma possível explicação para esse fato seria que a correção de gesso realizada em pré-semeadura de milho, na ausência de adubação nitrogenada em cobertura, tenha induzido menor absorção de S-sulfato na planta, ficando mais concentrado no solo. Segundo Epstein \& Bloom (2006), as absorções de N e de S pela planta são sinérgicas, uma vez que a deficiência de um desses nutrientes reprime a absorção do outro.

Os teores de $\mathrm{N}$ e S, determinados na diagnose foliar (Figura 5), evidenciam a dependência entre esses nutrientes na planta. Observa-se que o aumento no teor foliar de $\mathrm{N}$ é acompanhado de acréscimo no teor foliar de S, apesar de não haver diferença significativa entre os tratamentos. Neste estudo, os teores de $\mathrm{N}$ e $\mathrm{S}$ foliares mostraram-se adequados, segundo Bull \& Cantarella (1993).

As maiores produtividades de grãos foram

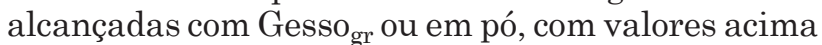
de 11 t ha $^{-1}$ de grãos, em relação à utilização de $\mathrm{U}+\mathrm{SA}_{\text {or }}$ ou U+SA $\mathrm{fa}_{\mathrm{fa}}$ (Quadro 3). Além do benefício inerente do fornecimento de $\mathrm{S}$ à cultura, pode ter havido lixiviação de bases, associada à lixiviação de sulfato de Gessogr $\mathrm{e}$ Gesso $_{\text {pó}}$. Os resultados de Votuporanga (Quadro 3) mostraram-se aparentemente opostos aos de Uberlândia (Quadro 3) para a aplicação de U+Gesso pó. Em solo arenoso haveria lixiviação mais intensa do sulfato, dados os reduzidos sítios de adsorção aniônica, diminuindo o contato com o sistema radicular e, conseqüentemente, sua absorção pela planta. Isso leva a pensar que, em solos arenosos, seria aconselhável a

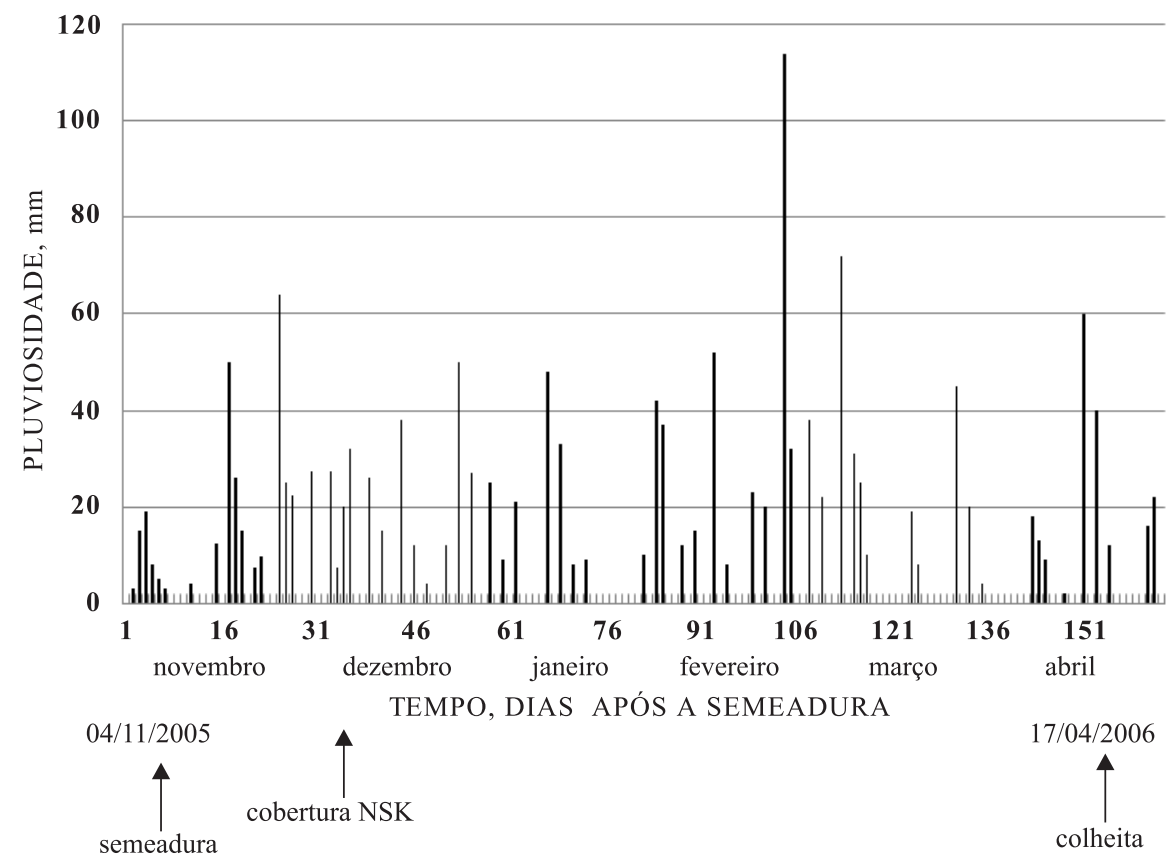

Figura 3. Distribuição da pluviosidade entre os meses de novembro de 2005 até abril de 2006. Uberlândia (MG). 
(a)

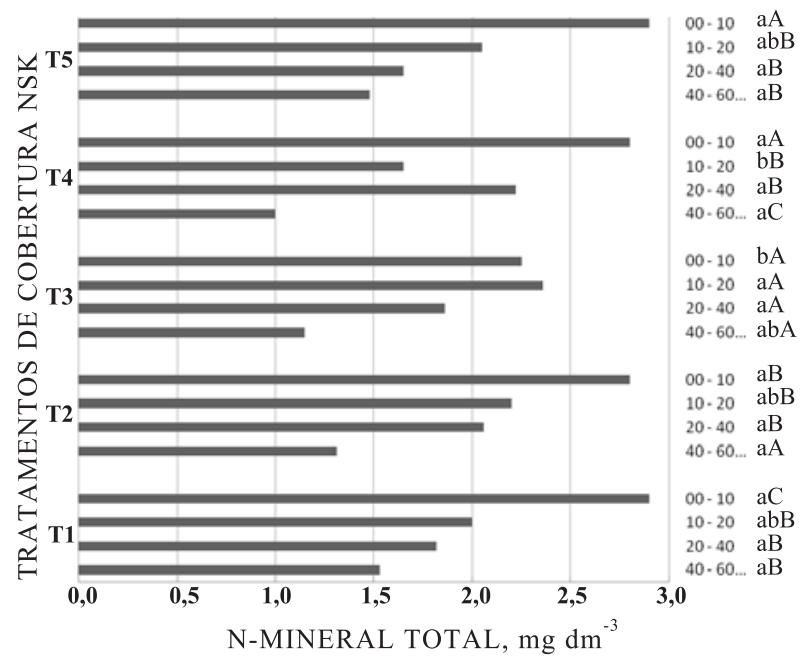

(b)

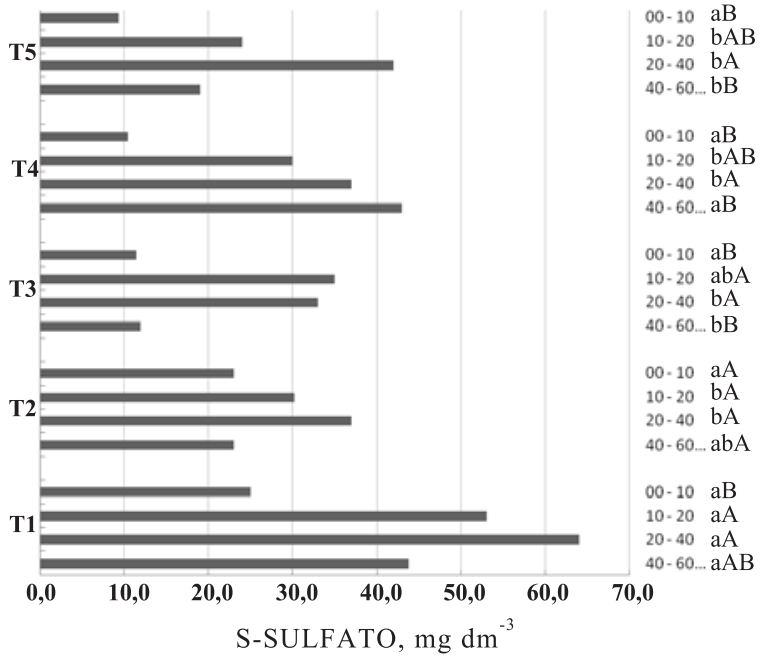

Figura 4. Distribuição em profundidade até $60 \mathrm{~cm}$ do N-mineral (a) e S-sulfato (b), 30 dias após efetuada a adubação de cobertura das fontes NSK de mistura de grânulos, na cultura de milho na safra 2005/2006. Uberlândia (MG). DMS (entre fontes) = 22,2; DMS (entre profundidades) = 20,8; CV $(\%)=36,8$; T1 = testemunha; $\mathrm{T} 2=\mathrm{U}+\mathrm{Sa}_{\mathrm{fa}} ; \mathrm{T} 3=\mathrm{U}+\mathrm{SA}_{\mathrm{gr}} ; \mathrm{T} 4=\mathrm{U}+\mathrm{Gesso}_{\mathrm{gr}} ; \mathrm{T} 5=\mathrm{U}+\mathrm{Gesso}_{\mathrm{pó}}$. Entre fontes, na mesma profundidade, as médias seguidas de letras minúsculas iguais não diferem estatisticamente a 0,05 pelo teste de Tukey. Entre profundidades, para cada fonte, as médias seguidas de letras maiúsculas desiguais diferem estatisticamente a 0,05 pelo teste de Tukey.

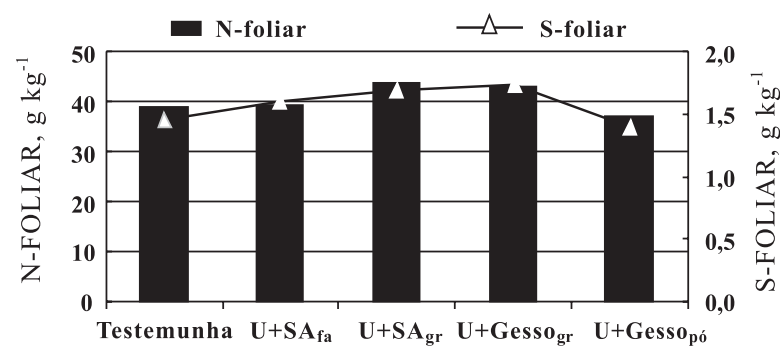

TRATAMENTOS DE COBERTURA

Figura 5. Teor de $\mathrm{N}$ e S-foliar, 30 dias após efetuada a adubação em cobertura, na cultura de milho na safra 2005/2006. Uberlândia (MG). utilização de gesso de forma granulada. Por outro lado, em solo argiloso a granulometria mais fina $\left(\right.$ Gesso $_{\text {pó})}$ teria maior possibilidade de contato com o solo e o sistema radicular, favorecendo sua absorção pela planta. Barros et al. (2005) afirmam que a eficiência do gesso depende de sua dissolução, a qual é influenciada por diversos fatores, como pela forma de aplicação e granulometria do corretivo.

Os custos dos insumos por tonelada, incluindo o frete entre Varginha (MG) e Uberlândia, flutuaram entre $\mathrm{R} \$ 700,00$ e $\mathrm{R} \$ 900,00$, sendo menor para $\mathrm{U}+\mathrm{Gesso}_{\mathrm{gr}}$, intermediário para as misturas de grânulos $\mathrm{U}+\mathrm{SA}$ e maior para o formulado NK,

Quadro 3. Produtividade de grãos e nitrogênio e enxofre exportado na cultura de milho, sob fertilizantes de cobertura aplicados na safra 2005/2006, contendo uréia+sulfato de amônio ou uréia+gesso. Uberlândia $(\mathrm{MG})^{(1)}$

\begin{tabular}{lccc}
\hline Tratamento & Produtividade & N total exportado & S total exportado \\
\cline { 2 - 3 } & & $\mathrm{kg} \mathrm{ha}^{-1}$ & $11,8 \mathrm{~b}$ \\
Testemunha & $9.321 \mathrm{~d}$ & $157,1 \mathrm{c}$ & $12,4 \mathrm{~b}$ \\
U + SA & $10.117 \mathrm{~cd}$ & $198,7 \mathrm{~b}$ & $12,6 \mathrm{~b}$ \\
U + SA & $10.483 \mathrm{bc}$ & $197,5 \mathrm{~b}$ & $12,6 \mathrm{~b}$ \\
U + Gessogr & $11.233 \mathrm{ab}$ & $206,2 \mathrm{~b}$ & $14,9 \mathrm{a}$ \\
U + Gesso pó & $11.494 \mathrm{a}$ & $239,1 \mathrm{a}$ & 1,3 \\
DMS (entre tratamentos) & 993 & 28,4 & 6,6 \\
CV (\%) & 6,1 & 9,2 &
\end{tabular}

\footnotetext{
(1) Em cada coluna, as médias seguidas de letras iguais não diferem significativamente a 0,05 pelo teste de $\mathrm{t}$ (Student). U+SA $\mathrm{fa}_{\mathrm{fa}}$

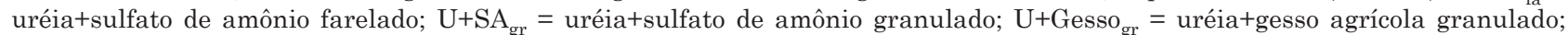
$\mathrm{U}+\mathrm{Gesso}_{\text {pó }}=$ uréia+gesso agrícola em pó.
} 
composto de $\mathrm{U}$ e $\mathrm{KCl}$, com aplicação posterior de gesso em pó (Quadro 4).

Com base na dose aplicada de $90 \mathrm{~kg} \mathrm{ha}^{-1}$ de $\mathrm{N}$ de cada mistura, aquelas com U+SA, granulada ou farelada, apresentaram menor custo de aplicação que a mistura U+Gessogr ou U+Gesso pó . A menor concentração de $\mathrm{N}$ e a dupla utilização de maquinário, para aplicação exclusiva de gesso (U+Gesso pó), aumentaram os custos de aplicação das misturas U+Gesso. Em relação aos custos diretos totais, para a produção de um hectare de milho, tomando como base o valor estimado por Richetti (2007), de $\mathrm{R} \$ 1.276,10$, houve em média 7,6 \% a menos em custos de aplicação das misturas U+SA em relação às misturas U+Gesso, independentemente da granulometria das fontes. Essa diferença não seria muito expressiva, a ponto de inibir a utilização do gesso, quando houvesse menos disponibilidade de sulfato de amônio.
4. Os custos de aplicação das formas uréia+gesso foram superiores aos das misturas de grânulos uréia + sulfato de amônio.

\section{AGRADECIMENTOS}

À Fundação de Amparo à Pesquisa do Estado de Minas Gerais (Fapemig), ao Convênio Embrapa Petrobras e ao produtor Fernando Ferraz, da Fazenda Floresta do Lobo, Pinusplan (MG), sem os quais não teria sido possível a execução deste trabalho. Agradecimentos especiais à Serrana Fertilizantes, pertencente ao Grupo Bunge Fertilizantes, pelo fornecimento das misturas utilizadas em cobertura, e ao Grupo Pioneer Sementes, pelo fornecimento das sementes de híbrido.

Quadro 4. Custos dos formulados e de aplicação e custos relativos da aplicação da cobertura na cultura do milho, em relação aos custos totais. Uberlândia (MG)

\begin{tabular}{|c|c|c|c|c|c|}
\hline \multicolumn{2}{|c|}{ Tratamento } & \multirow{2}{*}{$\begin{array}{c}\text { Custo } \\
\text { formulado }^{(2)}\end{array}$} & \multirow{2}{*}{$\begin{array}{c}\text { Dose } \\
\text { aplicada }^{(3)} \\
\mathrm{kg} \mathrm{ha}^{-1}\end{array}$} & \multirow{2}{*}{$\begin{array}{c}\text { Custo de } \\
\text { aplicação }^{(5)} \\
\mathrm{R} \$\end{array}$} & \multirow{2}{*}{$\begin{array}{c}\begin{array}{c}\text { Proporção custo da } \\
\text { cobertura/custo total }^{(6)}\end{array} \\
\%\end{array}$} \\
\hline Fontes & Formulados & & & & \\
\hline $\mathrm{U}+\mathrm{SA}_{\mathrm{gr}}$ & $24: 00: 06: 20$ & 874,72 & 379,0 & 366,1 & 28,7 \\
\hline $\mathrm{U}=\mathrm{SA}_{\mathrm{fa}}$ & $24: 00: 06: 20$ & 847,38 & 379,0 & 355,9 & 27,9 \\
\hline $\mathrm{U}+\mathrm{Gessogr}_{\mathrm{gr}}$ & 15:00:05:19 & 704,58 & 600,0 & 460,9 & 36,1 \\
\hline $\mathrm{U}+\mathrm{Gesso}_{\mathrm{po}}^{(1)}$ & $22: 00: 00: 30$ & 932,00 & $401,9^{(4)}$ & 454,8 & 35,6 \\
\hline
\end{tabular}

(1) Incluído o gesso em pó, aplicado em separado ( $\mathrm{R} \$ 11,00$ por tonelada). ${ }^{(2)}$ Valor posto em fazenda, incluindo o frete. (3) Dose calculada para aplicação de $90 \mathrm{~kg} \mathrm{ha}^{-1}$ de N. ${ }^{(4)}$ Custo real para a dose aplicada, incluindo a hora/máquina (R $\left.\$ 38,07\right)$. Na aplicação do gesso em pó foi considerado valor dobrado de hora/máquina. ${ }^{(5)}$ Incluindo a aplicação de gesso em pó (169 kg ha-1 equivalente a $22 \mathrm{~kg} \mathrm{ha}^{-1}$ de S). ${ }^{(6)}$ Custo total da produção de milho safra 2006/2007 (R\$ 1.276,10), segundo Richetti (2006).

\section{CONCLUSÕES}

1. Quanto à produtividade de milho, as fontes mistas de uréia+sulfato de amônio e uréia+gesso, independentemente da granulometria dos produtos utilizados, mostraram-se similarmente eficientes, nos municípios de Uberlândia (muito argiloso) e Votuporanga (arenoso), em solos de texturas diferentes.

2. Em solo arenoso do município de Votuporanga, as perdas por volatilização de $\mathrm{N}-\mathrm{NH}_{3}$ proveniente da mistura uréia + sulfato de amônio foram inferiores às determinadas com as misturas uréia + gesso.

3. Em solo muito argiloso do município de Uberlândia, após 30 dias da aplicação das fontes de cobertura nitrogenada, não houve diferença entre as misturas NSK na distribuição em profundidade do $\mathrm{N}$-mineral total, e o S-sulfato mostrou-se acumulado na subsuperfície do solo.

\section{LITERATURA CITADA}

BARROS, M.F.C.; FONTES, M.P.F.; ALVAREZ V., V.H. \& RUIZ, H.A. Aplicação de gesso e calcário na recuperação de solos salino-sódicos do Estado de Pernambuco. R. Bras. Eng. Agric. Amb., 9:320-326, 2005.

BULL, L.T. \& CANTARELLA, H. Cultura do milho: Fatores que afetam a produtividade. Piracicaba, POTAFOS, 1993. $301 \mathrm{p}$.

BURESH, R.J. Ammonia volatilization from point-placed urea in upland, sandy soils. Fert. Res., 12:263-268, 1987.

CANTARELlA, H. \& TRIVELIN, P.C.O. Determinação de nitrogênio total em solo. In: RAIJ, B. van; ANDRADE, J.C.; CANTARELLA, H. \& QUAGGIO, J.A., eds. Análise química para avaliação da fertilidade de solos tropicais. Campinas, Instituto Agronômico de Campinas, 2001. p.262-269. 
CANTARELla, H. \& PROCHNOW, L.I. Determinação de sulfato em solos. In: RAIJ, B. van; ANDRADE, J.C.; CANTARELLA, H. \& QUAGGIO, J.A., eds. Análise química para avaliação da fertilidade de solos tropicais. Campinas, Instituto Agronômico de Campinas, 2001. p.225-230.

EPSTEIN, E. \& BLOOM, A.J. Nutrição mineral de plantas: Princípios e perspectivas. 2.ed. Londrina, Editora Planta, 2006. 403p.

LARA CABEZAS, W.A.R. Marcação de vinhaça com ${ }^{15} \mathrm{~N}$ e avaliação de perdas gasosas de nitrogênio da vinhaça- ${ }^{15} \mathrm{~N}$ e uréia- ${ }^{15} \mathrm{~N}$ em solos cultivados com cana-de-açúcar (Saccharum spp). Piracicaba, Escola Superior de Agricultura "Luiz de Queiroz", 1991. 85p. (Tese de Doutorado)

LARA CABEZAS, W.A.R.; TRIVELIN, P.C.O.; BENDASSOLLI, J.A.; SANTANA, D.G. DE \& GASCHO, G.J. Calibration of a semi-open static collector for determination of ammonia volatilization from nitrogen fertilizers. Comm. Soil Sci. Plant Anal., 30:389-406, 1999.

LARA CABEZAS, W.A.R. \& SOUZA, M.A.S. Volatilização de amônia, lixiviação de nitrogênio e produtividade de milho em resposta à aplicação de misturas de uréia com sulfato de amônio ou com gesso agrícola. R. Bras. Ci. Solo, 2008. (Submetido a publicação neste número)

MALAVOLTA, E.; VITTI, G.C. \& OLIVEIRA, S.A. Avaliação do estado nutricional das plantas. 2.ed. Piracicaba, POTAFOS, 1997. 319p.

PORT, O.; AITA, C. \& GIACOMINI, S.J. Perdas de nitrogênio por volatilização de amônia com o uso de dejetos de suínos em plantio direto. Pesq. Agropec. Bras. 38:857865, 2003.
RAIJ, B. van; ANDRADE, J.C.; CANTARELLA, H. \& QUAGGIO, J.A. Análise química para avaliação da fertilidade de solos tropicais. Campinas, Instituto Agronômico de Campinas, 2001. 285p.

RICHETTI, A. Estimativa do custo de produção de milho, safra 2006/07, para Mato Grosso do Sul. Dourados, Embrapa Agropecuária Oeste, 2007. 8p. (Comunicado Técnico, 122)

SAMPAIO, M.A.P.M.; SCHOCKEN-ITURRINO, R.P.; SAMPAIO, A.A.M.; BERCHIELLI, S.C.P. \& BIONDI, A. Estudo da população microbiana e da liberação de amônia da cama de frangos tratada com gesso agrícola. Arq. Bras. Med. Vet. Zootec., 51:559-564, 1999.

SCHERER, H.W. Sulfur in crop production - invited paper. Eur. J. Agron., 14:81-111, 2001.

SILVA, V.M.; TRIVELIN, P.C.O.; COLAÇO, W.; ENCARNAÇÃO, F.A.F. \& LARA CABEZAS, W.A.R. Mineralização e volatilização do nitrogênio da vinhaça ${ }^{15} \mathrm{~N}$ na presença ou não de uréia e de palha de cana-deaçúcar. Sci. Agric., 56:117-124, 1999.

SILVA, V.R.; REICHERT, J.M.; STORCK, L. \& FEIJÓ, S. Variabilidade espacial das características químicas do solo e produtividade de milho em um Argissolo VermelhoAmarelo distrófico arênico. R. Bras. Ci. Solo, 27:10131020, 2003.

SOBRINHO, A.C.P.L.; AMARAL, A.J.R.; DANTAS, J.O.C. \& DANTAS, J.R.A. Gibsita. Disponível em: <http:// www.dnpm.gov.br/assets/galeriadocumento/ balancomineral2001/gipsita.pdf> Acesso em: 25 abr. 2007.

VITTI, G.C. \& HEINRICHS, R. Formas alternativas de obtenção e utilização do N e S: Uma visão holística. In: SIMPÓSIO NITROGÊNIO E ENXOFRE NA AGRICULTURA, Piracicaba, 2006. Anais. Piracicaba, GAPE/FEALQ/ ESALQ, 2006. CD-ROM. 